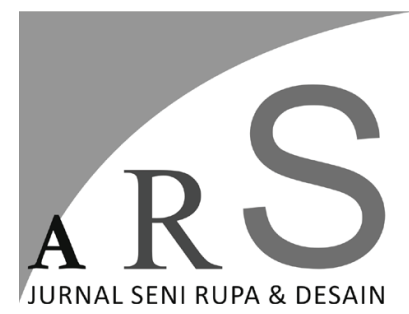

Volume 21 Nomor 3,

Desember 2018

\title{
BUSANA SULTAN HAMENGKU BUWONO IX DALAM PERSPEKTIF INTEGRASI STRUKTURAL
}

\section{Fitri Nuraeni}

\author{
Program Studi Kriya Seni, Jurusan Kriya \\ Fakultas Seni Rupa, Institut Seni Indonesia Yogyakarta \\ E-mail: timbulksg@yahoo.com
}

\begin{abstract}
ABSTRAK
GRM. Dorodjatun memiliki latar belakang kehidupan dan perjalanan hidup yang menarik, sehingga menarik untuk menjadikannya objek material dalam penelitian kualitatif ini. Rumusan masalah akan dibatasi pada busana Sultan Hamengku Buwana IX, sehingga dapat mengetahui busana apa saja yang dikenakan oleh Sultan Hamengku Buwana IX dan wujud dari busana tersebut. Objek formal dalam penelitian ini adalah perspektif Integrasi Struktural. Perspektif tersebut digunakan untuk mengurai busana Sultan Hamengku Buwono IX hingga bagian terkecil. Integrasi Struktural biasa diwujudkan dalam bentuk skematika yang penerapannya berisi alur berpikir penulis. Skema tersebut membantu dalam pembatasan masalah, pengumpulan data, dan pengelompokkan data. Pengumpulan data dilakukan dengan studi pustaka dan studi lapangan. Studi pustaka dengan mencari data baik dari buku, foto, maupun jurnal. Adapun studi lapangan dengan observasi dan wawancara. Segala sesuatu mengenai busana Sultan Hamengku Buwono IX akan dikaji menggunakan perspektif Integrasi Struktural. Penerapan perspektif Integrasi Struktural membuat kategorisasi busana Sultan Hamengku Buwono IX menjadi terstruktur. Kategorisasi mengenai jenis-jenis busana dan wujudnya dapat menjadi lebih mudah diselesaikan. Secara garis besar, busana Sultan Hamengku Buwono IX diklasifikasikan menjadi busana keraton dan busana nonkeraton.
\end{abstract}

Kata Kunci: busana, Sultan Hamengku Buwono IX, integrasi struktural

\section{ABSTRACT}

GRM. Dorodjatun has an interesting life background and life journey, so the author is interested in making it a material object in this qualitative research. The formulation of the problem will be limited to the clothing of Sultan Hamengku Buwana IX, so that he can find out what clothes are worn by Sultan Hamengku Buwana IX and the form of the clothing. The formal object in this research is the perspective of Structural Integration. This perspective was used to unravel the clothing of Sultan Hamengku Buwono IX to the smallest part. Structural Integration is usually manifested in the form of schematics whose application contains the author's thinking flow. Such schemes help in problem restrictions, data collection, and data grouping. Data collection was done by literature study and field study. Literature study by looking for data from books, photos, and journals. Field studies with observations and interviews. Everything about the clothes of Sultan Hamengku Buwono IX will be studied using Structural Integration perspective. The application of perspective of Structural Integration makes categorization of Sultan Hamengku Buwono $I X$ fashion become structured. The categorization of the types of clothing and their form can be more easily solved. Broadly speaking, the clothing of Sultan Hamengku Buwono IX is classified into court dress and non-royal clothing.

Keywords: clothing, Sultan Hamengku Buwono IX, structural integration 


\section{Pendahuluan}

Keraton

\section{Hadiningrat}

Kasultanan Ngayogyakarta pangeran Mangkubumi dalam menuntut haknya atas kerajaan Mataram. Sesuai Perjanjian Giyanti tahun 1755, maka kerajaan Mataram dibagi dua menjadi Kasunanan Surakarta Hadiningrat dan Kasultanan Ngayogyakarta Hadiningrat. Pangeran Mangkubumi yang bergelar Sultan Hamengku Buwono I kemudian ditetapkan sebagai raja pertama Kasultanan Ngayogyakarta Hadiningrat yang menurunkan raja-raja berikutnya. (Ricklef, Hadikusumo, \& Alkhatab, 2002: 79-92)(Ricklef et al., 2002)

Keraton Kasultanan Ngayogyakarta Hadiningrat sebagai pusat kebudayaan Jawa memiliki kekayaan budaya yang beraneka ragam. Salah satu kekayaan budaya yang dianggap penting di keraton Kasultanan Ngayogyakarta Hadiningrat adalah busana. Hal tersebut dapat dilihat dari adanya peraturan mengenai tata cara berbusana. Peraturan tersebut berupa Pranatan Dalem Bab Namanipun Panganggo Ing Nagari Ngayogyakarta Hadiningrat, 1927. (Condronegoro \& Mari, 1995:19) Busana tidak terbatas pada pakaian (atasan dan bawahan, bagian luar dan bagian dalam) saja, namun perpaduan dari pakaian, perlengkapan busana, dan tatanan rambut. Busana menjadi penanda lapisan sosial dan kebudayaan, sebagaimana yang dicontohkan oleh Nordholt dalam bukunya Outward Appearrances Trend, Identitas, Kepentingan, yaitu: mengenai keadaan yang akan tampak di suatu ruangan jika orang-orang yang berada di ruangan tersebut dalam kondisi telanjang. Mereka dengan segera kehilangan identitasnya. (Nordholt, Schulte, \& Azis, 2005:1) Hal tersebut memperjelas betapa pentingnya arti busana dalam konteks sosial, dengan kata lain busana menjadi sebuah penanda kebudayaan yang dapat mencerminkan asal-usul seseorang.

Raja keraton Kasultanan Ngayogyakarta Hadiningrat yang dimaksud dalam penelitian ini adalah Sultan Hamengku Buwana IX. Penulis memilih Sultan Hamengku Buwana IX, karena beliau adalah tokoh legendaris, cukup penting dan berani. Pernah menjabat dalam pemerintahan Republik Indonesia, salah satunya adalah sebagai wakil Presiden ke-2 setelah Drs. Muh. Hatta dari 24 Maret 1973- 23 Maret 1978. Hamengku Buwana IX adalah seorang sultan yang tidak dengan mudah menurut pada Belanda walaupun sejak usia empat tahun telah hidup bersama keluarga Belanda. Hal tersebut tercermin dalam pidato penobatannya sebagai Sultan Hamengku Buwana IX. Beliau mengatakan "Walaupun saya telah mengenyam pendidikan Barat yang sebenarnya, namun pertama-pertama saya adalah dan tetap adalah orang Jawa”. (Atmakusumah, 1982:52)

Penulis membuat kategorisasi busana Sultan Hamengku Buwana IX dari masa anak-anak hingga menjadi raja di keraton Kasultanan Ngayogyakarta Hadiningrat menggunakan perspektif Integrasi Struktural. Perspektif tersebut merupakan salah satu cara pandang yang berdasar pada struktur. Integrasi Struktural mempunyai suatu rumusan yang akan diterapkan oleh penulis untuk membuat kategorisasi busana Sultan Hamengku Buwana IX. Rumusan tersebut terdiri atas beberapa unsur yang biasanya berwujud skematika. Segala yang berhubungan dengan busana Sultan Hamengku Buwana IX akan dikaji menggunakan perspektif tersebut. Busana Sultan Hamengku Buwana IX dari masa anak-anak hingga menjadi raja di keraton Kasultanan Ngayogyakarta Hadiningrat oleh penulis dijadikan objek material, yaitu: hal yang dikaji. Busana yang menjadi objek material akan dikaji menggunakan Integrasi Struktural sebagai objek formalnya. Rumusan masalah akan dibatasi pada busana Sultan Hamengku Buwana IX, sehingga dapat mengetahui busana apa saja yang dikenakan oleh sultan Hamengku Buwana IX dan wujud dari busana tersebut.

Objek formal dalam penelitian ini adalah perspektif Integrasi Struktural. Perspektif tersebut digunakan untuk mengurai busana sultan Hamengku Buwono IX hingga bagian terkecil. Integrasi Struktural biasa diwujudkan dalam bentuk skematika yang penerapannya berisi alur berpikir penulis. Skema tersebut membantu 
dalam pembatasan masalah, pengumpulan data, dan pengelompokan data. Pengumpulan data dilakukan dengan studi pustaka dan studi lapangan. Studi pustaka dengan mencari data baik dari buku, foto, jurnal, maupun skripsi terdahulu, sedangkan studi lapangan dilakukan dengan observasi dan wawancara. Observasi dilakukan dengan mengamati secara langsung busana yang ada di keraton Yogyakarta, terutama di museum HB IX, dan wawancara dilakukan dengan mewawancarai abdi dalem keraton Kasultanan Ngayogyakarta Hadiningrat. Segala sesuatu mengenai busana sultan Hamengku Buwono IX akan dikaji menggunakan perspektif Integrasi Struktural. Perspektif tersebut diwujudkan dalam skematika sebagai berikut:

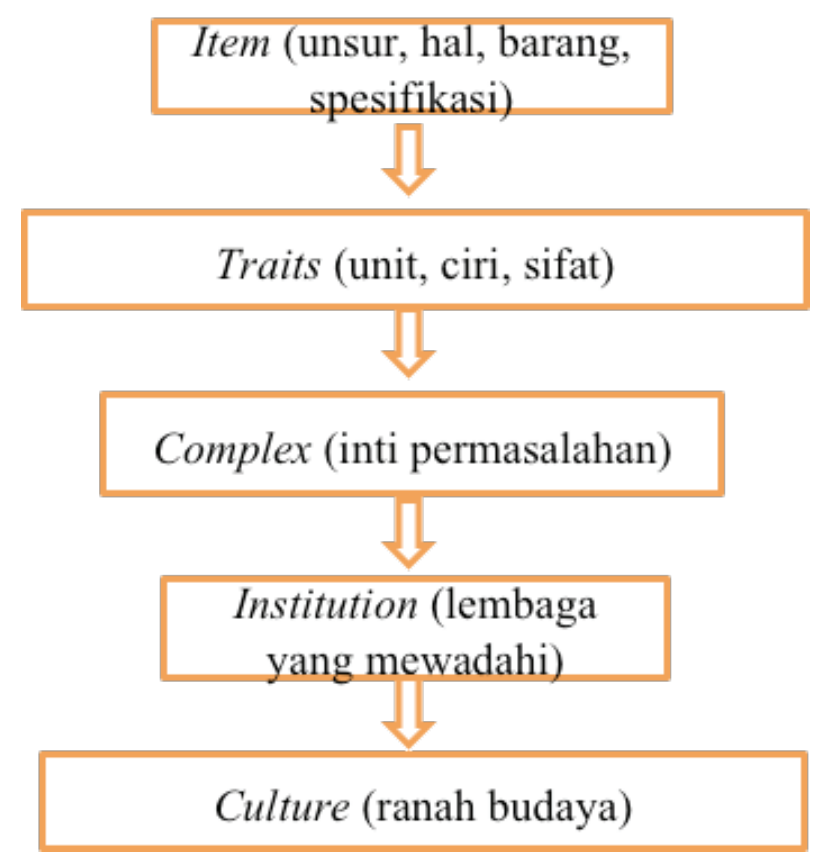

Skema 1. Integrasi Struktural

Penerapan perspektif Integrasi Struktural membuat kategorisasi busana Sultan Hamengku Buwono IX menjadi terstruktur. Kategorisasi mengenai jenis-jenis busana dan wujudnya dapat menjadi lebih mudah diselesaikan. Secara garis besar, busana Sultan Hamengku Buwono
IX diklasifikasikan menjadi busana keraton dan busana nonkeraton. Selain Integrasi Struktural, analisis data juga menggunakan teori pembacaan foto, seperti yang dilakukan Raap dalam bukunya yang berjudul Pekerdja di Djawa Tempo Doeloe dan Soeka-Doeka di Jawa Tempo Doeloe.

\section{Pembahasan}

Penyajian data dalam penelitian ini dimulai dengan menerapkan perspektif Integrasi Struktural. Semua yang berhubungan dengan busana Sultan Hamengku Buwana IX diuraikan relasi-relasinya untuk kemudian dianalisis. Penulis membuat skematika Integrasi Struktural busana Sultan Hamengku Buwana IX untuk memudahkan pemilihan data yang akan dianalisis. Kategorisasi atau pengelompokkan busana Sultan Hamengku Buwono IX berdasarkan data yang diperoleh oleh penulis. Keraton Kasultanan Ngayogyakarta Hadiningrat menjadi culture atau ranah budaya dalam penelitian ini. Keraton Kasultanan Ngayogyakarta Hadiningrat merupakan hasil perjuangan Pangeran Mangkubumi dalam menuntut haknya atas kerajaan Mataram. Sesuai Perjanjian Giyanti tahun 1755, Kerajaan Mataram dibagi dua menjadi Kasunanan Surakarta Hadiningrat yang dipimpin oleh Susuhunan Paku Buwana III dan Kasultanan Ngayogyakarta Hadiningrat dipimpin oleh Sultan Hamengku Buwana I. Pada tanggal inilah proklamasi atau Hadeging Nagari Ngayogyakarta Hadiningrat dikumandangkan. Selanjutnya, Sultan Hamengku Buwono I memulai pembangunan Keraton Yogyakarta pada tanggal 9 Oktober 1755. Pangeran Mangkubumi yang bergelar sultan Hamengku Buwono I kemudian ditetapkan sebagai raja pertama Kasultanan Ngayogyakarta Hadiningrat yang menurunkan raja-raja berikutnya. (Ricklef et al., 2002: 79-92) 


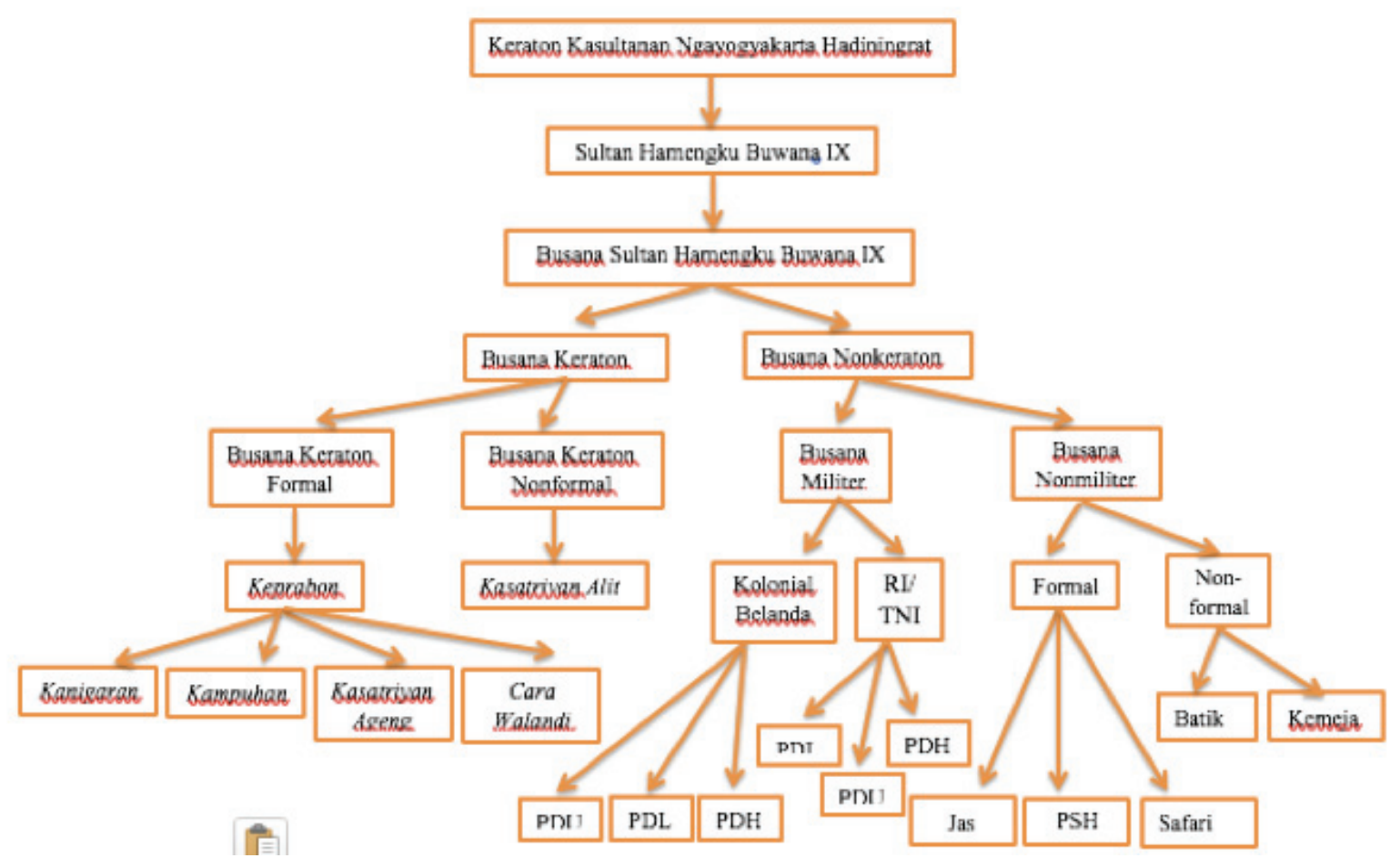

Skema 1. Integrasi Struktural Busana Sultan HB IX

Institusi dalam penelitian ini adalah Sultan Hamengku Buwana IX. Gusti Raden Mas Dorodjatun merupakan nama kecil Sultan Hamengku Buwana IX merupakan putra dari Sultan Hamengkubuwana VIII dengan istri ke-5 bernama Raden Ajeng Kustilah atau Kanjeng Ratu Alit. GRM. Dorodjatun dilahirkan pada Setu Paing, tanggal 12 April 1912 di kediaman Gusti Pangeran Haryo Puruboyo di Kampung Sompilan, Jalan Ngasem 13 Yogyakarta (sekarang dikenal sebagai Pakuningratan). Gusti Pangeran Haryo Puruboyo adalah orang yang nantinya menjadi Kanjeng Gusti Pangeran Adipati Anom Hamengku Negara, yaitu: putra mahkota Keraton Kasultanan Ngayogyakarta Hadiningrat yang kemudian dinobatkan sebagai Sultan Hamengku Buwono VIII. (Atmakusumah, 1982: 20-21) (Dorodjatun telah tinggal terpisah dari keluarganya sejak berumur 4 tahun. Kemudian melanjutkan belajar ke negeri Belanda. Hal tersebut merupakan kehendak dari ayahanda agar ia mendapatkan pendidikan Barat. Busana Sultan Hamengku Buwana IX merupakan complex atau inti permasalahan dari penelitian ini. Untuk traits-nya yang merupakan unit dari busana Sultan Hamengku Buwana IX terdiri atas dua bagian, yaitu: busana keraton dan busana nonkeraton. Dari masing-masing traits tersebut masih memiliki item.

Pada penelitian ini item tidak hanya terdiri atas satu tingkatan, namun ada traits yang memiliki dua tingkatan item dan tiga tingkatan item. Keadaan seperti ini dapat terjadi sesuai dengan data yang ditemukan dalam penelitian ini. Bagian busana keraton memiliki item busana keraton formal dan busana keraton nonformal. Busana keraton formal yang dimaksud adalah busana keprabon yang terdiri atas busana kanigaran, kampuhan, kasatriyan ageng, dan cara walandi. Sedangkan busana keraton nonformal adalah busana harian atau busana pedinan yang disebut dengan kasatriyan alit. Sama halnya dengan busana keraton, busana nonkeraton juga memiliki dua item, antara lain: busana militer dan busana nonmiliter. Kedua item ini juga masih dapat diuraikan lagi, sehingga item tidak hanya terdiri atas satu tingkatan. Busana militer dibedakan menjadi dua, yaitu: busana militer 


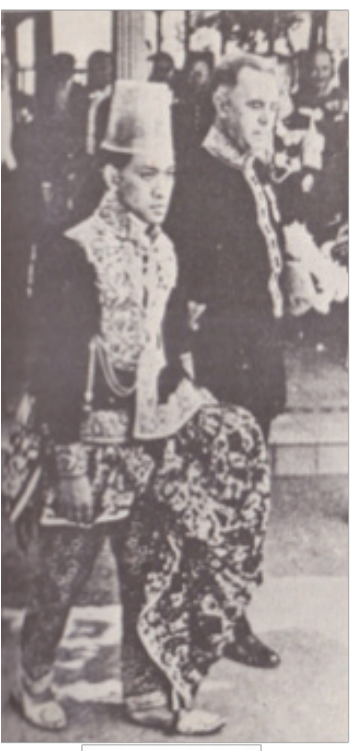

c

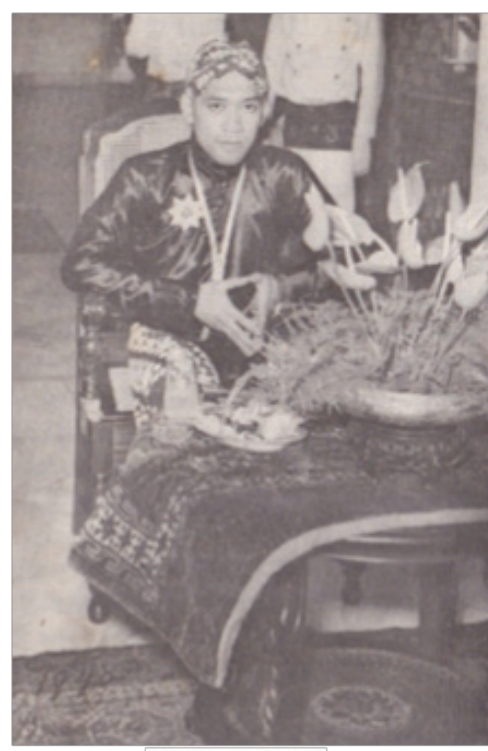

b

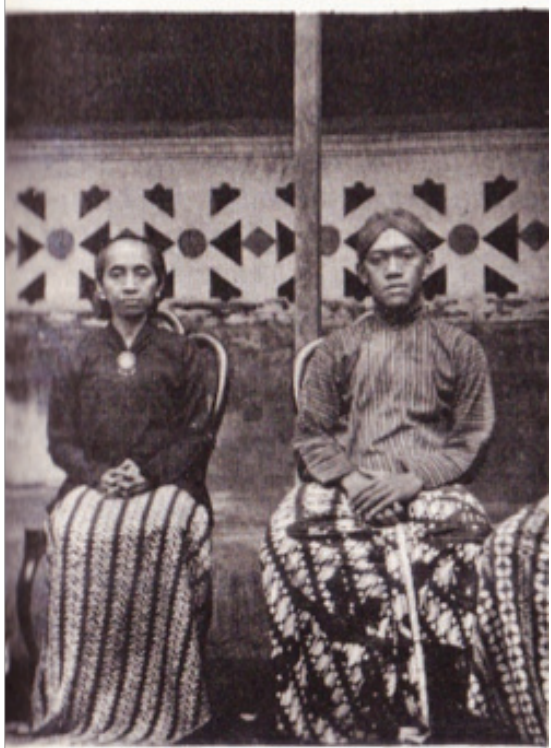

a

Gambar 1. a. Sultan Hamengku Buwana IX mengenakan busana kanigaran; b. Sultan Hamengku Buwana IX mengenakan busana kasatriyan ageng; c. Sultan Hamengku Buwana IX mengenakan busana kasatriyan alit.

(Sumber: Atmakusumah, 1982)

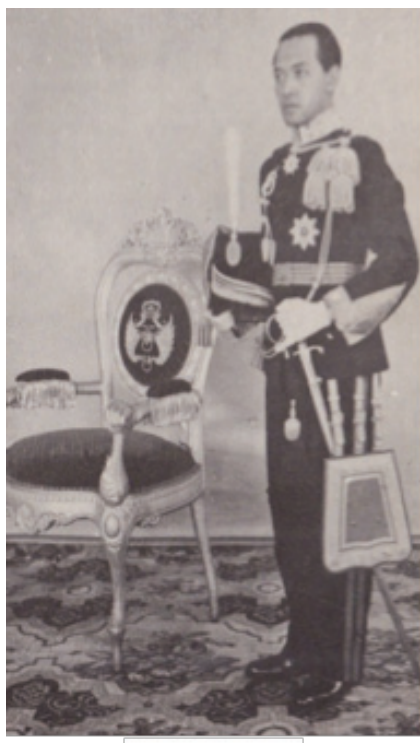

$\mathrm{c}$

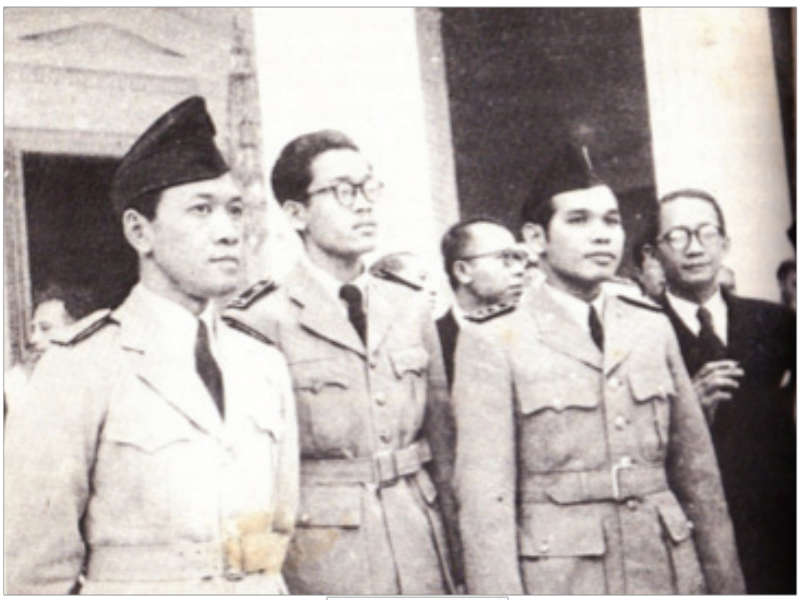

b

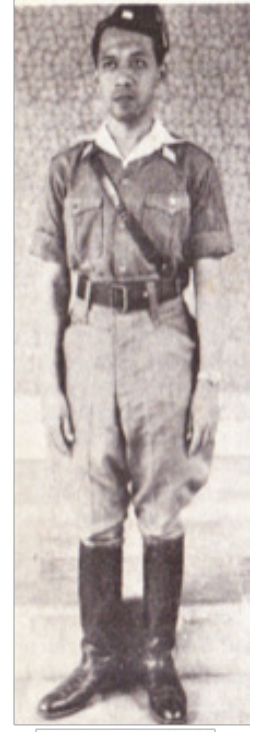

a

Gambar 2 a. Sultan Hamengku Buwana IX mengenakan busana militer KNIL; b. Sultan Hamengku Buwana IX mengenakan Pakaian Dinas Upacara TNI; c. Sultan Hamengku Buwana IX mengenakan busana Pakaian Dinas Lapangan TNI

(Sumber: Atmakusumah, 1982)

pada masa kolonial Hindia Belanda dan busana militer Republik Indonesia atau TNI. Busana militer kolonial Belanda dengan busana militer Republik Indonesia atau TNI diklasifikasikan lagi menjadi PDU (Pakaian Dinas Upacara), PDL (Pakaian Dinas Lapangan), dan PDH (Pakaian Dinas Harian). Busana nonmiliter terbagi menjadi dua bagian, yaitu: busana formal dan busana nonformal. Busana formal, antara lain: jas, baju safari, dan PSH (Pakaian Sipil Harian). Adapun busana nonformal ialah batik dan kemeja. Di bawah ini terdapat beberapa busana yang di kenakan oleh Sultan Hamengku Buwana IX baik busana keraton, maupun busana nonkeraton, sebagai berikut 


\begin{tabular}{|c|c|c|c|c|c|c|c|c|}
\hline \multirow{3}{*}{$\begin{array}{l}\text { Bagian } \\
\text { Busana }\end{array}$} & \multicolumn{6}{|c|}{ Busana Keraton } & & \\
\hline & \multicolumn{5}{|c|}{ Keprabon. } & \multirow{2}{*}{$\frac{\text { Redinas }}{\text { Kasatrósar. Alit }}$} & & \\
\hline & Kaniearan. & Kampubaa & $\begin{array}{l}\text { Kasatrivar } \\
\text { dgeng }\end{array}$ & Cara Walaodi & Sunitan. & & & \\
\hline $\begin{array}{l}\text { Renutan } \\
\text { Kepala }\end{array}$ & buluk & Kuiluk & blansbon. & blanskan. & topi.songkok & blansekon. & & \\
\hline Badas Atas & 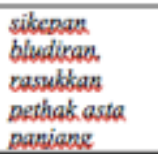 & $\cdot$ & sucian & seragam militer & CNIL. & & 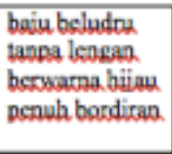 & surian \\
\hline $\begin{array}{l}\text { Badan } \\
\text { Bawah. }\end{array}$ & $\begin{array}{l}\text { kain kawowh. } \\
\text { laociasan } \\
\text { cindhe. }\end{array}$ & $\begin{array}{l}\text { kain barwewh } \\
\text { dan lawcingan } \\
\text { cindhe. }\end{array}$ & $\begin{array}{l}\text { wasampins } \\
\text { batik }\end{array}$ & serasamm militer & $\mathrm{CNIL}$ & & $\begin{array}{l}\text { maspoviog } \\
\text { batik }\end{array}$ & $\begin{array}{l}\text { myamping } \\
\text { batik }\end{array}$ \\
\hline Alas Kaki & Cenela & Cenela & cenela & sepatu & & & - & cenela \\
\hline $\begin{array}{l}\text { Perlengkapan } \\
\text { Busana }\end{array}$ & $\begin{array}{l}\text { sumping } \\
\text { mangkana, } \\
\text { kancing ukel, } \\
\text { lonthong. } \\
\text { moga, kamus, } \\
\text { timang epek- } \\
\text { epek, keris }\end{array}$ & $\begin{array}{l}\text { lonthong, } \\
\text { moga, kamus, } \\
\text { timang, epek- } \\
\text { epek, dan keris }\end{array}$ & $\begin{array}{l}\text { lonthong, } \\
\text { moga, kamus, } \\
\text { timang, epek- } \\
\text { epek dan keris }\end{array}$ & atribut seragam & niliter KNIL & & $\begin{array}{l}\text { stemping. } \\
\text { lonthong dan } \\
\text { kamus }\end{array}$ & $\begin{array}{l}\text { lonthong. } \\
\text { moga, kamus, } \\
\text { timang, epek- } \\
\text { epek, dan keris }\end{array}$ \\
\hline Perhiasan & $\begin{array}{l}\text { cincin, } \\
\text { bintang } \\
\text { kebesatan, } \\
\text { rante. karset }\end{array}$ & rante, karset & $\begin{array}{l}\text { nante, karset, } \\
\text { bros bunga }\end{array}$ & & - & & $\begin{array}{l}\text { sanssansan } \\
\text { sunesua dan } \\
\text { cincia }\end{array}$ & - \\
\hline
\end{tabular}

$\$$

Tabel 2. Bagian-Bagian Busana_NonKeraton

\begin{tabular}{|c|c|c|c|c|c|c|c|c|c|c|c|}
\hline \multirow{4}{*}{$\begin{array}{l}\text { Bagian } \\
\text { Busana }\end{array}$} & \multicolumn{11}{|c|}{ Busana Non-Keraton } \\
\hline & \multicolumn{6}{|c|}{ Busana Militer } & \multicolumn{5}{|c|}{ Busana Non-Militer } \\
\hline & \multicolumn{3}{|c|}{ KoloniaL Hindia Belanda } & \multicolumn{3}{|c|}{ TNI } & \multicolumn{3}{|c|}{ Busana Formal } & \multicolumn{2}{|c|}{$\begin{array}{l}\text { Busana Non- } \\
\text { Formal }\end{array}$} \\
\hline & PDU & PDL & PDH & PDU & PDL & PDH & Jas & PSH & Safari & Batik & Kemeja \\
\hline $\begin{array}{l}\text { Benutura } \\
\text { Kesala. }\end{array}$ & Trai & Irai & - & toai & topi & - & - & - & - & $\cdot$ & - \\
\hline Badan Atas & $\begin{array}{l}\text { seragam } \\
\text { militex } \\
\text { KNIL }\end{array}$ & $\begin{array}{l}\text { seragam } \\
\text { militec } \\
\text { KNIL }\end{array}$ & $\begin{array}{l}\text { seragama } \\
\text { militec } \\
\text { KNIL }\end{array}$ & $\begin{array}{l}\text { serasam } \\
\text { militer } \\
\text { TNI }\end{array}$ & $\begin{array}{l}\text { seragam } \\
\text { militec } \\
\text { TN1 }\end{array}$ & $\begin{array}{l}\text { seragam } \\
\text { militer } \\
\text { TNI }\end{array}$ & $\begin{array}{l}\text { kemeja } \\
\text { lengan } \\
\text { panjang } \\
\text { dan jas }\end{array}$ & $\begin{array}{l}\text { setelan } \\
\text { PSH }\end{array}$ & $\begin{array}{l}\text { setelah } \\
\text { Safari }\end{array}$ & $\begin{array}{l}\text { baju } \\
\text { bermotif } \\
\text { batik }\end{array}$ & $\begin{array}{l}\text { baju } \\
\text { lengan } \\
\text { panjang } \\
\text { atau } \\
\text { lengan } \\
\text { pendek } \\
\text { berkerah }\end{array}$ \\
\hline $\begin{array}{l}\text { Badan } \\
\text { Bawah }\end{array}$ & $\begin{array}{l}\text { seragam } \\
\text { militer } \\
\text { KNIL }\end{array}$ & $\begin{array}{l}\text { seragam } \\
\text { militer } \\
\text { KNIL }\end{array}$ & $\begin{array}{l}\text { seragam } \\
\text { militer } \\
\text { KNIL }\end{array}$ & $\begin{array}{l}\text { seragam } \\
\text { militer } \\
\text { TNI }\end{array}$ & $\begin{array}{l}\text { seragam } \\
\text { militer } \\
\text { TNI }\end{array}$ & $\begin{array}{l}\text { seragam } \\
\text { militer } \\
\text { TNI }\end{array}$ & $\begin{array}{l}\text { celana } \\
\text { panjang }\end{array}$ & $\begin{array}{l}\text { setelan } \\
\text { PSH }\end{array}$ & $\begin{array}{l}\text { setelah } \\
\text { Safari }\end{array}$ & $\begin{array}{l}\text { celana } \\
\text { panjang }\end{array}$ & $\begin{array}{l}\text { celana } \\
\text { panjang }\end{array}$ \\
\hline Alas Kaki & Sepatu & sepatu & sepatu & sepatu & sepatu & sepatu & sepatu & sepatu & sepatu & sepatu & sepatu \\
\hline $\begin{array}{l}\text { Perlengkapan } \\
\text { Busana }\end{array}$ & $\begin{array}{l}\text { tanda } \\
\text { pangkat, } \\
\text { dan } \\
\text { atribut } \\
\text { seragam } \\
\text { militer } \\
\text { KNIL }\end{array}$ & $\begin{array}{l}\text { tanda } \\
\text { pangkat } \\
\text { dan } \\
\text { atribut } \\
\text { seragam } \\
\text { militer } \\
\text { KNIL }\end{array}$ & $\begin{array}{l}\text { tanda } \\
\text { pangkat } \\
\text { dan } \\
\text { atribut } \\
\text { seragam } \\
\text { militer } \\
\text { KNIL }\end{array}$ & $\begin{array}{l}\text { tanda } \\
\text { pangkat } \\
\text { dan } \\
\text { atribut } \\
\text { seragam } \\
\text { militer } \\
\text { TNI }\end{array}$ & $\begin{array}{l}\text { tanda } \\
\text { pangkat } \\
\text { dan } \\
\text { atribut } \\
\text { seragam } \\
\text { militer } \\
\text { TNI }\end{array}$ & $\begin{array}{l}\text { tanda } \\
\text { pangkat } \\
\text { dan } \\
\text { atribut } \\
\text { seragam } \\
\text { militer } \\
\text { TNI }\end{array}$ & \begin{tabular}{l|} 
ikat \\
pinggang
\end{tabular} & \begin{tabular}{l|} 
ikat \\
pinggang
\end{tabular} & $\begin{array}{l}\text { ikat } \\
\text { pinggang }\end{array}$ & \begin{tabular}{l|} 
ikat \\
pinggang
\end{tabular} & $\begin{array}{l}\text { ikat } \\
\text { pinggang }\end{array}$ \\
\hline Perhiasan & $\begin{array}{l}\text { bintang } \\
\text { kebesaran } \\
\text { sultan } \\
\text { HB IX }\end{array}$ & - & - & - & $\begin{array}{l}\text { jam } \\
\text { tangan }\end{array}$ & $\begin{array}{l}\text { jam } \\
\text { tangan, }\end{array}$ & $\begin{array}{l}\text { bros } \\
\text { kecil dan } \\
\text { jam } \\
\text { tangan }\end{array}$ & $\begin{array}{l}\text { jam } \\
\text { tangan }\end{array}$ & $\begin{array}{l}\text { jam } \\
\text { tangan. }\end{array}$ & $\begin{array}{l}\text { jam } \\
\text { tangan. }\end{array}$ & $\begin{array}{l}\text { jam } \\
\text { tansan. }\end{array}$ \\
\hline
\end{tabular}

\section{Penutup}

Busana yang dikenakan oleh Sultan Hamengku Buwono IX beraneka macam jenisnya. Oleh karena itu, penulis membuat skematika busana Sultan Hamengku Buwono IX dalam perspektif Integrasi Struktural sebagai wujud dari alur berpikir. Pada skematika tersebut busana yang dikenakan oleh Sultan Hamengku Buwono IX diklasifikasikan menjadi dua, yaitu: busana keraton dan busana nonkeraton. Busana keraton diuraikan menjadi busana keraton formal dan busana keraton nonformal. Busana keraton formal, seperti busana keprabon (kanigaran, kampuhan, kasatriyan ageng, dan cara walandi) 
dan busana supitan. Busana keraton nonformal adalah busana kasatriyan alit. Busana tersebut dikenakan sebagai busana harian oleh Sultan Hamengku Buwono IX. Sebelum menjadi sultan hampir tidak ada busana kasatriyan alit yang tampak ia kenakan karena sejak usia empat tahun sudah dititipkan dan tinggal bersama keluarga Belanda. Setelah itu, hidup di negeri Belanda untuk melanjutkan pendidikannya. Tidak lama setelah kepulangannya ke tanah air, ia dinobatkan menjadi Sultan Hamengku Buwono IX.

Busana nonkeraton diklasifikasikan menjadi dua bagian pula, antara lain: busana militer dan busana nonmiliter. Busana militer diuraikan lagi menjadi busana militer pada pemerintahan kolonial Hindia Belanda dan busana militer Republik Indonesia atau TNI (Tentara Nasional Republik Indonesia). Masing-masing dari busana militer tersebut masih bisa diuraikan lagi menjadi PDU (Pakaian Dinas Upacara), PDL (Pakaian Dinas Lapangan), dan PDH (Pakaian Dinas Harian). Adapun busana nonmiliter masih dapat diklasifikasikan menjadi busana formal dan busana nonformal. Busana formal antara lain: jas, busana safari, dan PSH (Pakaian Sipil Harian). Busana nonformal ialah baju batik dan kemeja.

Sejak usia empat tahun Dorodjatun dititipkan oleh ayahanda (Sultan Hamengku Buwono VIII) untuk tinggal bersama keluarga Belanda. Sultan Hamengku Buwono VIII bermaksud agar anaknya mendapatkan pendidikan Belanda. Hidup dalam lingkungan keluarga Belanda menjadikan cara berpikir juga seperti orang Belanda, sikap disiplin pun terbentuk. Walaupun sejak usia empat tahun hidup dengan keluarga Belanda, Dorodjatun tetap menjadi manusia Jawa. Hal ini terlihat dari busana yang dikenakan.

\section{Daftar Pustaka}

Atmakusumah. (1982). Tahta untuk Rakyat Celah-Celah Kehidupan Sri Sultan Hamengku Buwana IX. Jakarta: Gramedia.

Condronegoro, \& Mari. (1995). Busana Adat 1877-1937 Kraton Yogyakarta: Makna dan Fungsi dalam Berbagai Upacara. Yogyakarta: Yayasan Pustaka Nusatama.

Nordholt, Schulte, H., \& Azis, I. (2005). Outward Appearances A Dressing State and Society in
Indonesia Terj. Outward Appearances Trend, Identitas, Kepentingan. Yogyakarta: LKIS.

Ricklef, M., Hadikusumo, H., \& Alkhatab, E. S. (2002). Jogjakarta under Sultan Mangkubumi 1749-1792 A History of the Division of Java, Terj. Yogyakarta di bawah Sultan Mangkubumi 1749-1792 Sejarah Pembagian Jawa. Yogyakarta: Matabangsa. 